\title{
Oxidation Treatment of Arsenic Sulfide Slag
}

\author{
Li Rui-bing1*, Yao Zhi-xin ${ }^{1}$, Zhang Ting-an ${ }^{2 *}$ and Yu San-san ${ }^{1}$ \\ ${ }^{1}$ Shenyang University of Chemical technology, Shenyang, China \\ ${ }^{2}$ Northeastern University, Shenyang, China
}

ISSN: 2576-8840

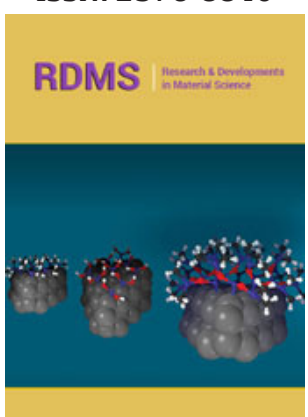

*Corresponding author: Li Ruibing, Shenyang University of Chemical technology, Shenyang, Liaoning, 110142, China

Zhang Ting-an, Northeastern University, Shenyang, Liaoning, 110819, China

Submission: 涀 August 06, 2021

Published: 淟August 17, 2021

Volume 15 - Issue 4

How to cite this article: Li Rui-bing, Yao Zhixin, Zhang Ting-an, Yu San-san. Oxidation Treatment of Arsenic Sulfide Slag. Res Dev Material Sci. 15(4). RDMS.000869. 2021. DOI: 10.31031/RDMS.2021.15.000869

Copyright@ Li Rui-bing and Zhang Ting-an. This article is distributed under the terms of the Creative Commons Attribution 4.0 International License, which permits unrestricted use and redistribution provided that the original author and source are credited.

\begin{abstract}
Large quantities of arsenic-containing toxic emissions are released during the smelting process of nonferrous minerals. The scrubbing process of flue gases from roasting furnaces, for example, produces a large amount of arsenic-containing acid sewage, and the latter, in turn, produces arsenic sulfide slag during the sulfide precipitation process. The arsenic sulfide slag is highly toxic and cannot be disposed of directly to the environment. It needs to be converted to some environment-friendly forms before disposal. With increasingly stringent requirements on environmental protection, more attention is being paid to the eco-friendly treatment of arsenic waste. The oxidation of arsenic sulfide slag can be the appropriate process. In the present paper, methods for treating arsenic sulfide residue waste are suggested; these include ferric sulfate oxidation leaching, hydrothermal treatment assisted by ferric nitrate, alkali leaching with air oxidation, sodium carbonate alkaline leaching, hydrogen peroxide oxidation leaching, etc. The possibilities of suggested processes in the industrial environment are also discussed.
\end{abstract}

Keywords: Arsenic sulfide slag; Trivalent arsenic oxidation; Arsenic removal

\section{Introduction}

Arsenic is generally present in the ores of copper, lead, zinc, and other non-ferrous metals. Most of the arsenic present is evolved in the form of gases during the smelting process. In general, arsenic oxides and arsenates are toxic and are to be removed from industrial emissions as well as from sewage. Similarly, the slags produced during the smelting process are required to be treated for arsenic removal using eco-friendly procedures. On the other hand, arsenic and its compounds also have useful applications; they are widely used in pesticides, alloymaking, and glass, semiconductors, and other industries. However, the limited demand for arsenic and its products does not match the large amounts of arsenic that can be retrieved from industrial waste. The imbalance poses a serious threat to environmental safety and thus the harmless treatment of arsenic is a serious concern.

In the smelting process of lead and zinc ores, $\mathrm{As}_{2} \mathrm{O}_{3}$ and $\mathrm{As}_{2} \mathrm{O}_{5}$ are emitted in the flue gases from the smelting/roasting furnaces; gases are treated, and the pollutants are washed into the acid sewage. By the sulfide precipitation method of the acid sewage, arsenic sulfide slag is produced. The main component of the slag is arsenic trisulfide while $\mathrm{Cu}, \mathrm{Na}, \mathrm{Bi}, \mathrm{Fe}$, and other elements are also present [1,2]. Arsenic sulfide slag is toxic, unstable, and can be oxidized to arsenic trioxide which is soluble in an acidic medium. Because of its fine particles size, it forms flying dust but it cannot be directly discharged into the atmosphere. In the early metallurgical processes, the pyrogenic process was generally used for arsenic removal. Because of the resulting serious air pollution, the pyrogenic process is no more used. The modern industrial processes are progressively looking towards more environment-friendly processes. For the consideration of environmental protection and economic viability, arseniccontaining waste slag is mainly treated by hydrometallurgical processes. The established approach to process arsenic sulfide slag, keeping in view comprehensive utilization of resources as well as environmental friendliness, is the conversion of trivalent arsenic into pentavalent. Pentavalent arsenic facilitates the precipitation process [3]. The oxidation 
leaching process is widely used in industrial arsenic elution. The present paper discusses the recent developments in the oxidation leaching of arsenic sulfide slag.

\section{Oxidation leaching of arsenic sulfide slag}

The arsenic sulfide slag treatment process can be of two types: the pyrogenic process and the hydrometallurgical process. The former includes oxidation roasting, reduction roasting, crystallization, etc. The pyrogenic processes are simple and the technology is mature while the disadvantages include serious air pollution and the low purity of the final product which is arsenic oxide. Pyrogenic processes for the treatment of arsenic-containing waste residue are almost abandoned. The present approach to process arsenic sulfide slag includes stabilization treatment and landfill treatment; the oxidation methods are the more popular ones. Many oxidation methods have been developed and these include hydrogen peroxide oxidation leaching, pressure oxidation leaching, sodium hypochlorite oxidation leaching [4].

\section{Acid oxidation leaching}

Oxidation leaching using ferric sulfate: Oxidation leaching of ferric sulfate is a method of leaching arsenic sulfide with ferric sulfate under high pressure [3]. Using $\mathrm{Fe}_{2}\left(\mathrm{SO}_{4}\right)_{3}$ as the oxidizing agent, trivalent arsenic is oxidized to pentavalent; the reaction takes place under high pressure. The processed $\mathrm{Fe}_{2}\left(\mathrm{SO}_{4}\right)_{3}$ can be recycled after oxidation which reduces the production cost. However, due to the high-pressure requirement, the production equipment is expensive and the process is complicated. The main reactions are as follows:

$$
\begin{aligned}
& \mathrm{As}_{2} \mathrm{~S}_{3}+3 \mathrm{Fe}_{2}\left(\mathrm{SO}_{4}\right)_{3}+4 \mathrm{H}_{2} \mathrm{O}=2 \mathrm{HAsO}_{2}+6 \mathrm{FeSO}_{4}+3 \mathrm{H}_{2} \mathrm{SO}_{4}+3 \mathrm{~S} \\
& \mathrm{HAsO}_{2}+\mathrm{Fe}_{2}\left(\mathrm{SO}_{4}\right)_{3}+2 \mathrm{H}_{2} \mathrm{O}=\mathrm{H}_{3} \mathrm{AsO}_{4}+2 \mathrm{FeSO}_{4}+\mathrm{H}_{2} \mathrm{SO}_{4}
\end{aligned}
$$

Copper sulfate replacement with the air oxidation process: The replacement reaction between copper sulfate and arsenic sulfide produces arsenious acid $\mathrm{HAsO}_{2}$ which has a low solubility. It is oxidized to arsenic acid whose solubility in the leaching solution increases if the air is bubbled through the solution. The process takes place at room temperature and atmospheric pressure which ensures safety and enhanced reliability. The process technology is mature, but the processing cost is high due to the complexity of the process $[5,6]$.

$$
\begin{aligned}
& \mathrm{As}_{2} \mathrm{~S}_{3}+3 \mathrm{CuSO}_{4}+4 \mathrm{H}_{2} \mathrm{O}=2 \mathrm{HAsO}_{2}+3 \mathrm{CuS}+3 \mathrm{H}_{2} \mathrm{SO}_{4} \text { (3) } \\
& \mathrm{HAsO}_{2}+1 / 2 \mathrm{O}_{2}+\mathrm{H}_{2} \mathrm{O}=\mathrm{H}_{3} \mathrm{AsO}_{4}(4)
\end{aligned}
$$

Sodium hypochlorite oxidation leaching process: Arsenic can be effectively removed from arsenic sulfide slag by sodium hypochlorite solution [7] since $\mathrm{CIO}^{-}$and $\mathrm{OH}^{-}$ions in the solution effectively oxidize and dissolve arsenic. The removal of arsenic by oxidation with sodium hypochlorite solution effectively accelerates the reaction to time durations of less than $10 \mathrm{~min}$ and the reaction is not sensitive to the temperature. The processes of desulfurization and arsenic leaching take place in a single step which makes the process simple and increases the production efficiency.

$$
\mathrm{As}_{2} \mathrm{~S}_{3}+6 \mathrm{OH}^{-}+5 \mathrm{CIO}^{-}=2 \mathrm{AsO}_{4}^{3-}+5 \mathrm{CI}^{-}+3 \mathrm{~S}+3 \mathrm{H}_{2} \mathrm{O}
$$

Scorodite process using hydrothermal treatment: The ferric arsenate $\left(\mathrm{Fe}^{3+}, \mathrm{AsO}_{4}^{3-}\right)$ precipitation is generally considered a stable arsenic-containing solid waste. The solubility of crystallized ferric arsenate $\left(\mathrm{FeAsO}_{4} \cdot 2 \mathrm{H}_{2} \mathrm{O}\right)$ is lower than that of amorphous. In hydrothermal oxidation of arsenic sulfide using $\mathrm{Fe}\left(\mathrm{NO}_{3}\right)_{3}$ as an oxidant, arsenic crystallizes as scorodite which is a stable hydrated iron arsenate compound. At $150^{\circ} \mathrm{C}$ the process can take place with $\mathrm{Fe}\left(\mathrm{NO}_{3}\right)_{3}$ even at dosages as low as $2 \mathrm{mmol} / \mathrm{g}[8,9]$.

$$
\begin{aligned}
& \mathrm{As}_{2} \mathrm{~S}_{3}+6 \mathrm{HNO}_{3}=3 \mathrm{~S}+2 \mathrm{H}_{3} \mathrm{AsO}_{4}+4 \mathrm{NO}_{2}+2 \mathrm{NO}(6) \\
& \mathrm{H}_{3} \mathrm{AsO}_{4}+\mathrm{Fe}\left(\mathrm{NO}_{3}\right)_{3}+2 \mathrm{H}_{2} \mathrm{O}=\mathrm{FeAsO}_{4} \cdot 2 \mathrm{H}_{2} \mathrm{O}+3 \mathrm{HNO}_{3} \text { (7) }
\end{aligned}
$$

\section{Alkaline oxidation leaching}

Alkali leaching with air oxidation: The arsenic sulfide can be leached by $\mathrm{NaOH}$ alkali solution at $70-80{ }^{\circ} \mathrm{C}$. After solid-liquid separation, the air is injected for oxidation [10]. The advantages of the process are: (i) air is used as the oxidant and (ii) the alkali can be regenerated which reduces the production cost. The reactions which take place are the following:

$$
\begin{aligned}
& \mathrm{As}_{2} \mathrm{~S}_{3}+2 \mathrm{NaOH}=\mathrm{NaAsO}_{2}+\mathrm{NaH}_{2} \mathrm{AsS}_{3}(8) \\
& \mathrm{As}_{2} \mathrm{~S}_{3}+4 \mathrm{NaOH}=\mathrm{NaAsO}_{2}+\mathrm{Na}_{3} \mathrm{AsS}_{3}+2 \mathrm{H}_{2} \mathrm{O}(9) \\
& \mathrm{As}_{2} \mathrm{~S}_{3}+6 \mathrm{NaOH}=\mathrm{Na}_{3} \mathrm{AsO}_{3}+\mathrm{Na}_{3} \mathrm{AsS}_{3}+3 \mathrm{H}_{2} \mathrm{O}(10) \\
& \mathrm{As}_{2} \mathrm{~S}_{3}+4 \mathrm{NaOH}+2 \mathrm{O}_{2}=\mathrm{NaAsO}_{2}+\mathrm{NaAsS}_{2}+\mathrm{Na}_{2} \mathrm{SO}_{4}+2 \mathrm{H}_{2} \mathrm{O}(11) \\
& \mathrm{NaAsO}_{2}+\frac{1}{2} \mathrm{O}_{2}+\mathrm{H}_{2} \mathrm{O}=\mathrm{NaH}_{2} \mathrm{AsO}_{4} \\
& \mathrm{NaH}_{2} \mathrm{AsS}_{3}+2 \mathrm{O}_{2}=\mathrm{NaH}_{2} \mathrm{AsO}_{4}+3 \mathrm{~S}(13) \\
& \mathrm{Na}_{3} \mathrm{AsS}_{3}+\frac{9}{2} \mathrm{O}_{2}+\mathrm{H}_{2} \mathrm{O}=\mathrm{NaH}_{2} \mathrm{AsO}_{4}+\mathrm{Na}_{2} \mathrm{SO}_{4}+\mathrm{SO}_{2}+\mathrm{S} \\
& \mathrm{NaAsS}_{2}+\frac{5}{2} \mathrm{O}_{2}+\mathrm{H}_{2} \mathrm{O}=\mathrm{NaH}_{2} \mathrm{AsO}_{4}+\mathrm{SO}_{2}+\mathrm{S} \\
& \mathrm{Na}_{3} \mathrm{AsO}_{3}+\frac{1}{2} \mathrm{O}_{2}=\mathrm{Na}_{3} \mathrm{AsO}_{4}(16)
\end{aligned}
$$

Alkaline leaching using sodium carbonate and sodium persulfate: Arsenic present in $\mathrm{Cu}$-As filter cakes can be leached using sodium carbonate solution [11] and the efficiency of arsenic elution exceeds 96\%. Arsenic in the leaching solution primarily exists in the form of arsenate and thioarsenate. Trivalent arsenic is oxidized to pentavalent and sulfur is oxidized to its elemental form by adding sodium persulfate to the leaching solution. The reactions are as follows:

$$
\begin{aligned}
& \mathrm{As}_{2} \mathrm{~S}_{3}+3 \mathrm{CO}_{3}^{2-}=\mathrm{AsO}_{3}^{3-}+\mathrm{AsS}_{3}^{3-}+3 \mathrm{CO}_{2} \text { (17) } \\
& \mathrm{AsS}_{3}^{3-}+8 \mathrm{OH}^{-}+4 \mathrm{~S}_{2} \mathrm{O}_{8}^{2-}=\mathrm{AsO}_{4}^{3-}+3 \mathrm{~S}+8 \mathrm{SO}_{4}^{2-}+4 \mathrm{H}_{2} \mathrm{O} \\
& \mathrm{AsO}_{3}^{3-}+2 \mathrm{OH}^{-}+\mathrm{S}_{2} \mathrm{O}_{8}^{2-}=\mathrm{AsO}_{4}^{3-}+2 \mathrm{SO}_{4}^{2-}+\mathrm{H}_{2} \mathrm{O} \text { (19) } \\
& \text { Other oxidation leaching methods }
\end{aligned}
$$

Oxidation leaching using hydrogen peroxide: Arsenic sulfide slag can be oxidized by air under natural conditions. With good ventilation conditions, sulfur ions in arsenic sulfide slag are oxidized by air into elemental sulfur at a very high oxidation rate, 
while the efficiency of arsenic leaching is $57.8 \%$ after 12 days [12]. Being a strong oxidant, hydrogen peroxide would react violently with arsenic sulfide slag, to form $\mathrm{AsO}_{4}^{3-}$; the leaching efficiency of arsenic would exceed 90\% [13].

Pressure oxidation leaching process: In the process of pressure oxidation leaching, industrial oxygen is used to leach out $\mathrm{H}_{3} \mathrm{AsO}_{4}$ from arsenic sulfide slag. Sulfur in the slag is oxidized to elemental sulfur which stays as solid in the slag. The leaching solution is then reduced using $\mathrm{SO}_{2}$ to form crystallized white arsenic flakes $\mathrm{As}_{2} \mathrm{O}_{3}$. The parent solution having a high concentration of sulfuric acid can be recycled [6]. During the process, the high pressure enhances the leaching efficiency; the process is simple and economical.

\section{Summary}

This paper reviews different processes to oxidize arsenic sulfide slag which is produced during the smelting of non-ferrous metals. The arsenic sulfide slag is oxidized into pentavalent arsenic using different oxidants; oxidation of arsenic sulfide is a prerequisite for subsequent processes.

In the beginning, ferric sulfate oxidation leaching and copper sulfate replacement reaction along with air oxidation methods were used. These processes are matured but are complex and so the equipment is expensive; both the capital investment as well as the running cost is high. An additional problem in these production processes is the production of sewage which would cause secondary pollution. From the point of view of efficiency, using hydrogen peroxide, sodium hypochlorite, and some other oxidants, the reaction process is accelerated and the production efficiency is increased but the economic benefit is not so high. It is concluded that factors that are important in deciding the treatment route of arsenic sulfide waste slag are the properties of the arsenic slag, the target requirements, and the treatment cost.

\section{Acknowledgement}

The authors are grateful to the Open project of key Laboratory of Ministry of Education for the financial support (Grant No. NEMM2020001).

\section{Conflict of Interest}

There are no conflicts to declare.

\section{References}

1. Ostermeyer P, Bonin L, Folens K, Verbruggen F, García-Timermans C et al. (2021) Effect of speciation and composition on the kinetics and precipitation of arsenic sulfide from industrial metallurgical wastewater. Journal of Hazardous Materials 409: 124418.

2. Battaglia-Brunet F, Crouzet C, Burnol A, Coulon S, Morin D, et al. (2012) Precipitation of arsenic sulphide from acidic water in a fixed-film bioreactor. Water Research 46(12): 3923-3933.

3. Lee Y, Um I, Yoon J (2003) Arsenic (III) Oxidation by Iron (VI) (Ferrate) and Subsequent Removal of Arsenic (V) by Iron (III) coagulation. Environ Sci Technol 37(24): 5750-5756.

4. Nazari AM, Radzinski R, Ghahreman A (2017) Review of arsenic metallurgy: Treatment of arsenical minerals and the immobilization of arsenic. Hydrometallurgy 174: 258-281.

5. Liu SL, Li JH, Meng WJ, Feng SB, Tang DY (2009) Current situation of resource recovery treatment technology of arsenic sulfide residues. Phosphate \& Compound Fertilizer 24(04): 60-63.

6. Li L, Jiang KX, Liu DX, Wang HB (1998) Oxidative pressure leaching of arsenic sulfide residues. Mining \& Metallurgy (04):47-51.

7. Li XH, Li ZQ Guo M (2014) Study on the technology of one step leaching arsenic from rich arsenic residue using sodium hypochlorite. Journal of Guangxi University: Nat Sci Ed 39(06): 1399-1402.

8. Zhang W, Lu H, Liu F, Wang C, Zhang Z, et al. (2021) Hydrothermal treatment of arsenic sulfide slag to immobilize arsenic into scorodite and recycle sulfur. Journal of Hazardous Materials 406: 124735.

9. Ma X, Gomez MA, Yuan Z, Zhang G, Wang S, et al. (2018) A novel method for preparing an as (V) solution for scorodite synthesis from an arsenic sulphide residue in a Pb refinery. Hydrometallurgy 183: 1-8.

10. Darban AK, Aazami M, Meléndez AM, Abdollahy M, Gonzalez I (2011) Electrochemical study of orpiment $\left(\mathrm{As}_{2} \mathrm{~S}_{3}\right)$ dissolution in a $\mathrm{NaOH}$ solution. Hydrometallurgy 105(3): 296-303.

11. Wu JH, Zhang XP, Dong B, Wu J, Chen XS, et al. (2019) Arsenic removal from $\mathrm{Cu}$-As-containing filter cakes by $\mathrm{Na}_{2} \mathrm{CO}_{3}$ leaching. Russian Journal of Non-Ferrous Metals 60(4): 372-379.

12. Lu Q, Du Y, Du DY (2016) Recovery of sulphur and arsenic from arsenic sulphide residue. Sulphuric Acid Industry 1: 24-27.

13. Gu K, Li W, Han J, Liu W, Qin W, et al. (2019) Arsenic removal from leadzinc smelter ash by $\mathrm{NaOH}-\mathrm{H}_{2} \mathrm{O}_{2}$ leaching. Separation and Purification Technology 209: 128-135. 